\title{
O trabalho no Brasil: traçado interpretativo de sua história de formação e de sua crítica
}

\author{
HEINZ DIETER HEIDEMANN ${ }^{I}$, \\ CARLOS DE ALMEIDA TOLEDO II \\ e CÁSSIO ARRUDA BOECHAT III
}

\section{Introdução}

RGUmentar a existência de uma crise do trabalho no Brasil não é tão
incomum. Isso resulta do relativo consenso atual sobre a capacidade
crescente de produzir riqueza com a redução de trabalho necessário. Não se pode afirmar, ao mesmo tempo, que o trabalho tenha deixado de ser a forma de acesso da maioria da população a produtos necessários para a reprodução de suas vidas.

Estudado como um metabolismo natural, o trabalho parece ser a essência humana, a isso chamamos de fetichismo do trabalho, naturalização de uma relação social historicamente determinada, uma objetividade contraditória e por isso em transformação. Tomado como simples produtor de matéria, o trabalho está constantemente se autossuperando. Nunca é demais lembrar que alguns dos mais banais produtos de hoje representaram no passado signos de riqueza e distinção social, sendo superados no momento seguinte por novos signos. Popularizadas as materialidades difundem-se, chegam ao consumo das periferias das metrópoles, onde trabalhadores expropriados se amontoam sem conseguir vender sua força de trabalho de forma estável e mesmo legalizada; mesmo assim, cada vez utilizam mais mercadorias. Ao mesmo tempo, o dinheiro, signo por excelência da riqueza, superacumula-se em quantidades impossíveis de serem absorvidas por investimentos produtivos, disputando ativos no jogo frenético dos mercados financeiros.

O excesso de força de trabalho no mercado, sem deixar de reduzir os salários a valores desmoralizantes para o trabalhador, torna-se um problema insolúvel para a gestão do território. A naturalização do trabalho se manifesta no estranhamento em pensar uma sociedade em crise por não precisar do trabalho de seus cidadãos. A crítica da naturalização exige o estudo do processo de formação da sociedade, o que envolve a problematização das escalas do território.

Nesse sentido, estudos da territorialização do capital, como processo de formação das relações de trabalho, tanto pelo uso de violência extraeconômica 
quanto de econômica, têm sido realizados por um grupo de pesquisadores ligados ao Laboratório de Geografia Urbana do Departamento de Geografia (DG FFLCH USP). ${ }^{1}$ Partindo de uma revisão crítica dos autores clássicos brasileiros, tais estudos resultaram nas formulações que ora apresentamos sem poder detalhar as relações de trabalho particulares de cada objeto empírico. Recorremos por isso à problematização das especificidades e particularidades com foco na escala territorial do Estado nacional desde sua formação.

\section{Valor e trabalho:}

\section{objetos de interesse da territorialização do capital}

À partida, o trabalho na modernização se caracteriza pelas diferenças perceptíveis em seu produto. Que os produtos do trabalho sejam diferentes entre si é um pressuposto da divisão do trabalho e, como será argumentado, o próprio Estado nacional brasileiro é um resultado da divisão territorial do trabalho e não uma comunidade que decidiu conscientemente por essa forma de organização territorial.

O que faz das diferenças entre processos de trabalho especificidades secundárias, meras particularidades, é a reprodução do objeto do trabalho, configurando profissões, posições internas da divisão do trabalho a serem personificadas por sujeitos reificados, e seus interesses são atributos dessa posição territorialmente condicionada. Se esse sujeito é, de fato, um sujeito jurídico do território do Estado nacional brasileiro, sua subjetividade, como trabalhador do território universalizado pelo capital mundial, faz de seus objetivos meros suportes do automovimento do dinheiro.

Numa medida, todos procedemos socialmente como personificações do capital, o que não anula, mas explica, a existência de desiguais apropriações desse e de posições sociais diferenciadas. A miséria da vida cotidiana não evita que os que nela se encontram tenham que se mediar socialmente acessando dinheiro e mercadorias. Essa condição, hoje em vias de generalização, resulta de um processo.

A variedade de trabalhos remete à variedade de mercadorias deles decorrentes, mas também à variedade de necessidades de uma sociedade complexificada. A concepção de tão diversas atividades concretas sob a qualidade de trabalho representa o seu caráter abstrato. Essa abstração real reitera-se como violência que força ao trabalho e que exige a troca constante de tempo de vida por ganhos monetarizados, fundamento fetichista do valor nessa sociedade. Enquanto a atividade se espreme na camisa de força do trabalho, essa mesma moldura se reproduz enquanto forma social, postulando a validade social de atividades das mais diversas. No limite, porém, essa validade só é efetiva quando representa para o trabalhador o recebimento do salário, ou, de outro ponto de vista, quando permite a obtenção do lucro, direta ou indiretamente pela exploração do trabalho alheio.

Além disso, como se sabe desde a teoria do valor-trabalho de Adam Smith (1974, p.69-70), uma parte da divisão do trabalho dedica-se exclusivamente à 
transformação do processo de trabalho, visando reduzir a quantidade de trabalho socialmente necessário à produção. Sendo assim, o trabalho também não permanece o mesmo no processo de modernização. A diferenciação do processo de trabalho, mesmo na produção de um mesmo produto, tende a transformar-se, mesmo quando o produto final permaneça sem nenhuma transformação sensível.

A coisa produzida como mercadoria precisa ser vendida e precisa ser conhecida pelo consumidor que dela virá a necessitar. A dependência de coisas novas parece ter como pressuposto o poder da publicidade sobre o consumidor, mais um trabalho nesse metabolismo em constante reterritorialização.

A expansão do capital não pode ser paralisada, mesmo quando as famílias não têm mais dinheiro para consumir. Por isso, o poder de fazer comprar da publicidade divulga também o meio de comprar sem ter dinheiro para pagar. $\mathrm{O}$ crédito é mais um dos estímulos ao consumo, cada vez mais difundido, legal ou ilegal, defendido pelas diversas mediações de trabalho implicadas pelos setores privados que se ampliam desde a cobrança até a execução jurídica, passando pela elaboração de leis etc., ou nas práticas ilegais pelo medo da execução - termo este, como se vê, que serve tanto para a intervenção jurídica, visando à restituição dos padrões de legalidade, como para a intervenção violenta do crime, restituindo os seus padrões igualmente violentos de "justiça".

À multiplicação de necessidades acarretada pela diversificação das mercadorias produzidas articula-se uma constelação de novos tipos de trabalhos, muitos dos quais sem remeter diretamente a uma atividade produtora de mercadorias. As "necessidades" de mediação social parecem se desdobrar em "necessidades" de novas formas de burocratização, controle e representação social. Mesmo assim, é preciso criticar a ampliação da riqueza das nações defendida por Adam Smith (1974), a miríade de tipos de trabalhos criados pela divisão do trabalho não pode mais compensar a redução do trabalho necessário possibilitada pelo avanço técnico.

Um enunciado em termos abstratos, entretanto, requer que nos perguntemos sobre a validade dessa formulação para casos a priori apresentados como específicos, do mesmo modo que requer um questionamento da validade dessa constatação para outros momentos históricos, sempre retomando uma perspectiva histórica.

Isso implica estudar processos específicos, mas é necessário perguntar sobre a existência de formas que agrupem diferentes trabalhos em relação à suas escalas territoriais historicamente determinadas. Tais formas territoriais específicas, forjadas pela divisão internacional do trabalho, podem ser apresentadas no processo de territorialização do capital que viria a formar um Estado nacional, o Brasil, como um "capítulo secundário" (Prado Jr., 1965, p.26) da modernização. A situação e a caracterização interessam-nos, pois, como já foi escrito, "a colônia revela o segredo da metrópole" (Marx, 1996, L.1, cap.25). 
Trata-se de estabelecer distinções entre as formas territoriais relativas à inserção da produção realizada no interior do território do Estado nacional, problematizando a reprodução das relações de trabalho. Tais relações sociais de produção indicam que o sentido do processo é a internalização no/pelo próprio trabalhador da violência que obriga ao trabalho, naturalizando o trabalho como sua condição de reprodução individual e/ou familiar aparentemente apartada da totalidade social.

Nesses termos, o trabalho no Brasil não seria mais do que a consolidação da forma territorial inerente à própria territorialização do capital. Em síntese, a especificidade do trabalho no Brasil estaria ligada aos momentos particulares da territorialização da forma elementar do capital, a mercadoria: uma história da imposição do trabalho, sendo o próprio trabalho (abstrato) o elemento que nega especificidades ao processo, impondo às diferenças um caráter de particularidade da totalidade territorial.

\section{Do escravismo ao Estado nacional: o conceito de região}

A existência de especificidades nas relações de trabalho é debatida no conceito de região econômica e politica por Francisco de Oliveira (1977), em Elegia para uma re(li)gião. O conceito estabelece um diálogo com a "Teoria da Moderna Colonização”, de Karl Marx (1996, cap.25), segundo o qual, na ausência da expropriação completa do trabalhador, política e economia não podem se autonomizar.

Assim, a colônia é escravista, pois o acesso à terra é difícil de limitar e, por isso, revela o segredo da metrópole, onde o trabalhador expropriado dos meios de produção não produzidos (a base fundiária) é obrigado a vender sua força de trabalho no mercado, sob o imperativo da concorrência e da superpopulação relativa. Nas condições da colônia, formam-se regiões caracterizadas, por Francisco de Oliveira, como formas sociais fundidas, agindo localmente na mobilização do trabalho para a acumulação primitiva do capital. Como afirma Oliveira (1977, p.31 - grifos do autor), no caso brasileiro:

um dos travejamentos básicos da estrutura de relações do feudalismo, a posse da propriedade dos meios de produção pelos produtores diretos não existiu desde o princípio: ao contrário, a escravidão era a forma peculiar pela qual se separou produtores e meios de produção como pressuposto da própria fundação da colônia nos quadros do capitalismo mercantil.

O conceito de região proposto pelo autor não resulta de uma formação social pré-capitalista, mas é específica da totalidade capitalista, ainda que marcada por relações de trabalho não salariais. Essa proposição remete à conclusão do capítulo "O sentido da colonização" de Formação do Brasil contemporâneo de Caio Prado Jr. (1965, p.26) no qual comenta:

Com tais elementos [os elementos são o europeu especulando, investindo cabedais e os indígenas e negros importados como mão de obra], articulados numa organização puramente produtora, industrial se constituirá a 
colônia brasileira, se gravará profunda e totalmente nas feições e na vida do país. Haverá resultantes secundárias que tendem para algo mais elevado; mas elas ainda mal fazem-se notar [escreve em 1942]. O "sentido" da evolução brasileira, que é o que estamos aqui indagando, ainda se afirma por aquele caráter inicial da colonização. Tê-lo em vista é compreender o essencial deste quadro que se apresenta em princípios do século passado. (As observações entre colchetes são dos autores do artigo)

Note-se a ênfase no caráter instrumental das relações de mobilização do trabalho e até mesmo das personificações do capital colonial. De um lado, os que perderam o domínio do território, indígenas e negros, reterritorializados em um processo que realiza o sentido da colonização, transformando-os em trabalhadores sob violência explícita; de outro lado estão os gestores do território, as personificações do poder colonial, a classe dominante branca. Vale a pena observar que a redução de tais relações à relação econômica não é uma abstração nominal, mas real, dada pelo processo. A imposição do trabalho na vida social, reproduzindo o território com relações escravistas, é criticada, mas não como patriarcal, aspecto inegável, mas pela indiferença ao sujeito escravizado insustentável moralmente. Mais ainda nos termos já humanistas do século XIX, e nesse sentido inorgânica, não podendo ser confundida com uma evolução espontânea e, muito menos, natural. ${ }^{2}$

A especificidade das áreas colonizadas na territorialização do capital explicita-se nas transformações não simultâneas entre as escalas territoriais. No que se refere à escala da totalidade, a acumulação primitiva que possibilitou a revolução industrial, na Inglaterra, mobilizou não só os trabalhadores expropriados que viriam a se assalariar nas fábricas, mas dependeu da mobilização escravista nas colônias. Vale lembrar a tese de Fernando Novais (1995, p.70) sobre o sentido profundo da colonização:

a colonização do Novo Mundo na Época Moderna apresenta-se como peça de um sistema, instrumento da acumulação primitiva da época do capitalismo mercantil. [...] consoante com [o] processo histórico concreto de constituição do capitalismo e da sociedade burguesa. Completa-se, entrementes, a conotação do sentido profundo da colonização: comercial e capitalista, isto é, elemento constitutivo no processo de formação do capitalismo moderno.

A segunda escala de análise sobre as especificidades das relações de trabalho na territorialização do Estado nacional brasileiro é a escala regional. Essa escala deve ser interpretada como um momento da territorialização do Estado nacional. Superado o capitalismo mercantil, a colônia, como parte do território da metrópole, sofre uma transformação com a queda do exclusivo metropolitano. Essa transformação leva Oliveira $(1977$, p.28) à sua formulação sobre as regiões: "são espaços econômicos que nasceram ou foram insertados na divisão internacional do trabalho do capitalismo mercantil como reservas e produtores de acumulação primitiva e que, posteriormente, continuam subjugados à divisão internacional do trabalho do capitalismo imperialista". 
$\mathrm{O}$ argumento, segundo o qual as regiões continuariam subjugadas à divisão internacional do trabalho do capitalismo em seu momento imperialista, diverge das teses que, no limite, interpretam esse momento como feudal. Trata-se de compreender o processo dessa reprodução de territórios por meio de diferentes relações de trabalho que revelam contradições entre os desdobramentos territoriais das relações entre metrópole e colônia. A territorialização do capital é a transformação dos padrões territoriais em diferentes escalas na qual a violência para mobilizar o trabalho é central.

Essa interpretação das relações territoriais revela a formação dos Estados nacionais como ligada intrinsecamente ao capital. Não haveria um espaço econômico senão como percepção autonomizada do processo. A territorialização do Estado nacional é a forma particular necessária à territorialidade do capital como totalidade, ou seja, como espaço de poder em processo de reprodução contraditória que forma o Estado nacional.

\section{Do momento regional ao nacional}

Pesquisas sobre as regiões no processo de territorialização do capital mobilizando trabalho sustentam que as regiões são marcadas por relações de trabalho não assalariadas, sendo momento do processo de expropriação que cria as condições para o assalariamento. ${ }^{3}$ Reconhecemos, por isso, que as relações de trabalho não assalariadas conferem a aparência de atraso às regiões. Sugerimos, porém, que esse ponto de vista dualista, ao naturalizar o padrão de territorialidade do Estado nacional formado, acaba sendo favorável à expropriação dos trabalhadores de seus meios de produção.

A existência de especificidades nos padrões de territorialidade das regiões refere-se à necessidade do emprego direto de violência extraeconômica para que se possa acumular capital. Vale dizer, o sentido do processo estudado com atenção à escala da totalidade é a acumulação de capital, enquanto nas regiões realiza-se em processos particulares de expropriação.

Isso não significa que não exista uma escala de Estado no processo de territorialização. No caso do Estado nacional brasileiro, a Guarda Nacional aparece como forma institucional do poder regional. Essa instituição nos parece marcar as formas especiais de reprodução do capital, e por consequência forma especial de luta de classes, onde o econômico e o político se fusionam como argumenta Oliveira (1977, p.29). Trata-se da forma institucional reconhecida do domínio territorial pelo Estado brasileiro até o fim da Primeira República.

Essa crítica ao dualismo não deixa de reconhecer diferenças entre metrópole e colônia, mas as compreende por sua relação. Esse conceito de região explicita a relação entre terra, trabalho e capital, articulando-o à dominação social apresentada na crítica de Marx à economia política. Dessa forma, a dominação territorial é explicada pelo fetichismo da mercadoria, que critica a separação comumente naturalizada entre esses três fatores de produção, que remete aos moldes da economia política. 
Para que o capital seja uma relação social de dominação, a terra tem que ser uma mercadoria transacionada em um monopólio de classe e, portanto, o trabalhador precisa ser expropriado dos meios de reproduzir sua existência autonomamente. Marx (1986, L. III, cap.23) chamou de autonomização a separação entre terra, trabalho e capital: essa pode ser revelada pelo estudo da reprodução material como sendo aparente, somente possível de ser afirmada em razão da propriedade de três fatores de produção - irredutíveis uns aos outros - geradores de renda da terra, salários e juros. Porém, é a dependência do trabalhador alicerçada sobre a necessidade de vender sua força de trabalho aos proprietários dos meios de produção para poder reproduzir-se o que revela a economia como violência. Essa violência econômica, internalizada pelo trabalhador, acaba por se opor à violência extraeconômica, caracterizada pelo padrão jurídico estatal consolidado historicamente.

A "Teoria Moderna da Colonização" (Marx, 1996, cap.25), que fecha o primeiro livro de $O$ capital, discute as condições para a expansão territorial do capital. ${ }^{4}$ As condições sociais na região são marcadas pelo fato de que a terra não é monopólio de classe, no sentido de um mercado autonomizado, o que implica que as relações de trabalho dependam da coerção direta, da violência privada para mobilizar trabalho. $\mathrm{O}$ que parece ser uma territorialidade não especificamente capitalista ${ }^{5}$ pode ser interpretado como momento da imposição forçada da territorialidade capitalista, imposição do trabalho, é importante reforçar. Dessa perspectiva, o que determina se há ou não capitalismo é a dinâmica da totalidade em processo e não uma forma particular de imposição das territorialidades regionais, momentos da territorialização do capital.

Por isso, para compreender as particularidades das relações de trabalho no território do Estado nacional brasileiro é preciso levar a sério o conceito de região de Francisco de Oliveira (1977, p.30) como:

espaços socioeconômicos onde uma das formas do capital se sobrepõe às demais homogeneizando a "região" exatamente pela sua predominância e pela consequente constituição de classes sociais cuja hierarquia e poder são determinados pelo lugar e forma em que são personas do capital e de sua contradição básica.

Nesse sentido, as formas particulares de relações de trabalho, ainda que possam se repor em lugares determinados, precisam ser problematizadas em suas relações com o território do Estado nacional e com a totalidade territorial que transcende as fronteiras desses Estados.

A seguir será feita uma problematização do trabalho em condições similares ao escravo no território do Estado nacional brasileiro contemporâneo. A problematização argumenta que não se trata de um fenômeno específico, mas de um desdobramento das condições de reprodução das relações territoriais do capital, não mais como um momento do processo de formação de um padrão territorial de fronteira, mas da própria degradação das relações de trabalho no 
território de um Estado nacional em que as relações de violência encontram-se devidamente juridificadas.

\section{O trabalho contemporâneo em condições análogas à escravidão}

A violência impondo as relações de trabalho, como apresentamos antes, depende de contextos territoriais, das condições de acesso dos trabalhadores aos meios de produção utilizados em sua reprodução. Por isso é preciso problematizar fenômenos empiricamente localizados tendo em vista as escalas da territorialização. Convém, nesse sentido, apresentar uma análise do debate sobre a persistência da escravidão no Brasil contemporâneo.

A pedido da Comissão Nacional Para a Erradicação do Trabalho Escravo (Conatrae), a Repórter Brasil (2014a) organizou uma página especial sobre a PEC do Trabalho Escravo, na qual afirma:

A Proposta de Emenda Constitucional 438/2001 foi aprovada por 360 votos em segundo turno na Câmara dos Deputados na noite desta terça-feira, 22. Dos 414 presentes, além dos que se mostram favoráveis, 29 votaram contra e 25 se abstiveram [...]. Eram necessários 308 votos favoráveis para a PEC do Trabalho Escravo avançar. A vitória foi comemorada com os parlamentares cantando o Hino Nacional. [...] A medida determina o confisco de propriedades em que for flagrado trabalho escravo e seu encaminhamento para reforma agrária ou uso social.

Como se percebe, não se trata de uma questão ocultada sob os olhos coniventes do poder estabelecido. A vitória foi comemorada, com os parlamentares cantando o Hino Nacional, indicando o empenho e a tensão de uma batalha que visa garantir os direitos dos trabalhadores (Repórter Brasil, 2014b). Além disso, não se trata de uma daquelas questões que podem ser acusadas de defesa de interesses corporativos de segmentos em favor próprio; trata-se da conquista de uma legislação para os segmentos mais frágeis dos trabalhadores que se reproduzem no território do Estado nacional brasileiro.

A definição de trabalho escravo é ampla, possibilitando o uso da legislação para diversas situações, tais como aquelas em que o trabalhador não consegue se desligar do patrão por fraude ou violência, quando é sujeito a condições desumanas ou é obrigado a trabalhar tão intensamente que sua vida é colocada em risco. Trabalho escravo, além de desrespeito a leis trabalhistas, é apresentado como violação aos direitos humanos. Veja-se que o artigo 149 do Código Penal, que prevê cadeia para quem se utilizar dessa prática, é de 1940, e foi reformado em 2003 tornando-se mais claro.

A perspectiva defendida pelos apoiadores da PEC do trabalho escravo não considera sua definição de trabalho escravo como idêntica ao escravismo colonial, observe-se o trecho a seguir do mesmo documento:

o trabalho escravo foi formalmente abolido em 13 de maio de 1888 e o Estado passou a considerar ilegal um ser humano ser dono de outro. O que permaneceram foram situações semelhantes ao trabalho escravo, tanto do 
ponto de vista de cercear a liberdade quanto de suprimir a dignidade do tra-

balhador, tratando-o como uma coisa, um objeto comercializado, não como um ser humano. (Repórter Brasil, 2014b)

Note-se que, abolida a possibilidade de se conceber um trabalhador como propriedade privada de outro homem, a prática do escravismo torna-se crime. A razão de ser daquilo que vem sendo chamado de escravismo não se confunde com a identidade entre a propriedade de escravos e riqueza. Parece tratar-se antes de uma possibilidade de reduzir os custos relacionados ao trabalho.

Essa transformação revela os poderes sobre o trabalho no atual território do Estado nacional brasileiro, que não pode ser confundido com um Estado sustentado por uma classe dominante atrasada. As práticas consideradas escravistas não se restringem a situações que poderiam ser caracterizadas como de fronteira. Apoiado nessa diferença, José de Souza Martins (1999, p. 131) argumenta que "uma significativa indicação de equívocos interpretativos que atravessam o desencontro de conceituação e ação é o pouco ou nenhum caso que faz do problema numericamente muito mais significativo da disseminação da superexploração do trabalho, também, e sobretudo, entre trabalhadores urbanos."

Tais conflitos não mais seriam, para o autor, "disputa pela propriedade da terra (um meio de trabalho) e a renda territorial”, cujo "processo característico é a expropriação". Tendo como "processo característico a exploração”, essa outra escravidão tem o trabalho como eixo. Observamos, pois, uma mudança na articulação entre violência econômica e extraeconômica na mobilização do trabalho, o que implica uma transformação do padrão de territorialidade do Estado nacional. A percepção da mudança na forma do conflito social, reconhecida por Martins (1999, p. 137), aponta para uma transformação importante:

Vários dos casos confundidos com escravidão diziam e dizem respeito [...] a formas de terceirização do trabalho - de transferência das responsabilidades trabalhistas aos próprios trabalhadores - que estão se difundindo rapidamente na indústria e também estão ocorrendo no campo [...] Essa modalidade de cativeiro, portanto, se insere perfeitamente na lógica da empresa capitalista moderna. [...] os trabalhadores, mesmo os organizados em sindicatos, vão se convencendo de que mais importante do que salários é o emprego, o que vai gerando uma classe trabalhadora politicamente débil e impossibilitada de lutar por seus direitos.

A crítica prática do capital ao processo de trabalho reduz constantemente a sua necessidade de trabalhadores, mesmo estando constantemente à beira da superprodução. A terceirização é um fenômeno mundial de reformulação do padrão de territorialidade especialmente nas metrópoles mundializadas. Não havendo especificidade nas relações de trabalho que reproduzem o território do Estado nacional brasileiro, impera o cativeiro da empresa capitalista moderna. Por isso, a Organização Internacional do Trabalho (OIT) e a relatora para formas contemporâneas de escravidão das Nações Unidas, Gulnara Shahinian, elogiam o conceito brasileiro de trabalho escravo (Repórter Brasil, 2014b). 
É claro que a Organização Internacional do Trabalho discute leis e empenho político em seu cumprimento, podendo pedir mais rigor ao sistema jurídico de execução da violência extraeconômica. Não parece, porém, disposta a refletir sobre os desdobramentos catastróficos da acumulação especificamente capitalista. Até porque não conduz sua crítica humanista do escravismo à crítica do poder econômico no assalariamento. Trata-se de um anacronismo já comentado por Marx (1986, p.206, nota 120).

Verdadeiramente engraçado é o senhor Bastiat, que imagina que os antigos gregos e romanos teriam vivido apenas do roubo. Quando porém se vive muitos séculos do roubo, tem que haver constantemente algo para roubar, ou seja, o objeto do roubo tem que reproduzir-se incessantemente. [...] Ou talvez Bastiat queira dizer que um sistema de produção, que se baseia em trabalho escravo, se apoia num sistema de roubo? Ele coloca-se, então, em terreno perigoso. Se um gigante do pensamento como Aristóteles, em sua apreciação do trabalho escravo, errou, por que deveria um economista anão em sua apreciação do trabalho assalariado acertar?

Mas as organizações mobilizam trabalho assalariado, por isso é necessária a autocrítica do trabalhador, ou para usar palavras de Martins $\left(1999\right.$, p.138) ${ }^{6}$ a "revisão crítica das próprias concepções e do próprio conhecimento, consequentemente da própria prática". Mais do que nunca é necessário desnaturalizar o trabalho assalariado, o que implica perceber a forma de mobilização do trabalho pelo Estado nacional, em territorialização e crise de reprodução. ${ }^{7} \mathrm{O}$ limite da terceirização é exposto por Kurz (2003) nos seguintes termos:

Os "supérfluos", multiplicando-se aos montes, precisam ser disciplinados e forçados a aceitar seu destino de maneira ainda mais dura que os "ocupados". Assim como no nascimento do capitalismo a colonização interna e a externa se condicionavam mutuamente, agora o novo colonialismo externo, ligado à crise, da polícia ocidental do mundo, sob a liderança dos EUA, vira um colonialismo interno, também ligado à crise, da administração da pobreza.

O processo socioeconômico da individualização nos Estados ocidentais da indústria e da prestação de serviços não é anulado por conta disso. Mas agora todos os "empresários de si mesmos" e os aventureiros fracassados da autovalorização podem sentir que o anonimato das coerções sistêmicas assume, na realidade da crise, a face dos vigias e dos capatazes, dos "oficiais e suboficiais do capital" (Marx). O tom das casernas voltou: de novo ouvimos berros, somos escarmentados, humilhados, insultados, tudo para não esquecermos o que a maravilhosa modernidade da economia de mercado é segundo sua essência: uma relação de coerção social.

Se à partida a territorialização do Estado nacional caracterizou as relações de mobilização do trabalho escravos como instrumentais, o padrão de territorialidade do Estado nacional brasileiro, fundado na expropriação dos trabalhadores que explora, mantém o caráter instrumental da mobilização do trabalho. Triste 
conclusão dos mais de setenta anos que nos separam da publicação de Formação do Brasil contemporáneo de Caio Prado Jr. (1965, p.26): permanecemos sem conseguir notar resultantes secundárias que tendam para algo mais elevado.

\section{Notas}

1 Ver bibliografia do grupo do Labur após as referências deste artigo e o artigo "Vinte anos de um grupo de estudos do LABUR - crise e crítica do sistema fetichista produtor de mercadoria e da modernização retardatária brasileira", publicado na Revista do Departamento de Geografia (Toledo et al., 2012, p.154-70).

2 Por isso, ressaltamos mais adiante a forma como a Economia Política tratou a escravidão das colônias como artificial em oposição ao assalariamento da metrópole, este natural.

3 Algumas das pesquisas realizadas por um grupo de estudantes do Programa de Geografia Humana no Labur do Depto. de Geografia da FFLCH-USP propõem a formulação teórica aqui delineada. Ver referências.

4 Há importantes pontos em comum entre o argumento aqui desenvolvido pela leitura de autores brasileiros com o conceito de $O$ ajuste espacial: Hegel, von Thünen e Marx, de Harvey (2005, cap.4).

5 A conhecida formulação de José de Souza Martins (2000) encontra-se em O cativeiro da terra e baseia-se na definição de modo de produção especificamente capitalista que pode ser encontrada em O capital (Marx, 1996, L.I, cap.10 e 23). Não se trata de corrigir o autor, mas de explorar de outra maneira a forma contraditória por ele percebida.

6 A crítica ao movimento social em defesa do Estado nacional que faz Martins não parece seguir a sábia recomendação. Ao interromper sua crítica no reconhecimento da existência da terceirização parece naturalizar a exploração juridificada do trabalho, sugerindo o monopólio da violência nas mãos do Estado como padrão de territorialidade insuperável.

7 Ver referências citadas na nota 1 e ainda os estudos de Alves (2006), Giavarotti (2013) e Pitta (2012).

\section{Referências}

HARVEY, D. O ajuste espacial: Hegel, von Thünen e Marx. In: HARVEY, D. A produção capitalista do espaço. São Paulo: Annablume, 2005. p.93-124.

KURZ, R. Acabou-se a brincadeira: A viragem do espírito do tempo ocidental: regresso da autorresponsabilização ao autoritarismo coercivo. 2003. Disponível em: <http:// obeco.planetaclix.pt/rkurzl35.htm>. Acesso em: 10 jun. 2014.

MARTINS, J. S. O cativeiro da terra. 8.ed. São Paulo: Hucitec, 2000.

A escravidão nos dias de hoje e as ciladas da interpretação. In: VV. AA.

Trabalho escravo no Brasil contemporâneo. São Paulo: CPT; Loyola, 1999.

MARX, K. O capital - critica da economia política. Livro 3. São Paulo: Nova Cultural, 1986.

1996.

O capital - critica da economia politica. Livro 1. São Paulo: Nova Cultural, 
NOVAIS, F. A. Portugal e Brasil na crise do antigo sistema colonial (1777-1808). São Paulo: Hucitec, 1995.

OLIVEIRA, F. de. Elegia para uma re(li)gião: Sudene, Nordeste. Planejamento e conflito de classes. Rio de Janeiro: Paz e Terra, 1977.

PRADO JUNIOR, C. Formação do Brasil contemporâneo: Colônia. São Paulo: Brasiliense, 1965.

REPÓRTER BRASIL. PEC do Trabalho Escravo é aprovada na Câmara dos Deputados. 22 de maio de 2012. Disponível em: <http://www.trabalhoescravo.org.br/noticia/62>. Acesso em: 10 jun. 2014a.

Perguntas e respostas sobre trabalho escravo. Disponível em: <http://www.trabalhoescravo.org.br/conteudo/tres-mentiras-sobre-o-trabalho-escravo>. Acesso em: 10 jun. 2014 b.

SMITH, A. Investigação sobre a natureza e as causas da riqueza das nações. São Paulo: Abril Cultural, 1974. (Coleção “Os pensadores”).

Bibliografia selecionada do Grupo de Estudos do Labur

ALVES, V. E. L. Formação territorial sul pianiense: modernização agropecuária e resistência camponesa. 2000. Dissertação (Mestrado em Geografia Humana) - Faculdade de Filosofia, Letras e Ciências Humanas, Universidade de São Paulo. São Paulo, 2006.

BOECHAT, C. A. Região do colonato: mobilização do trabalho e autonomização do capital na área de Olímpia (1857-1964) do Oeste Paulista. 2009. Dissertação (Mestrado) - Faculdade de Filosofia, Letras e Ciências Humanas, Universidade de São Paulo. São Paulo, 2009.

. O colono que virou suco: terra, trabalho, Estado e capital na modernização da citricultura paulista. 2013. Tese (Doutorado) - Faculdade de Filosofia, Letras e Ciências Humanas, Universidade de São Paulo. São Paulo, 2013.

FUJIKAVA, R. Geografia do exterminio e povoamento do norte do Paraná: a violência necessária na franja pioneira paulista (1930-1960). 2013. Mestrado (Dissertação) - Faculdade de Filosofia, Letras e Ciências Humanas, Universidade de São Paulo. São Paulo, 2013.

GIAVAROTTI, D. M. O Jardim Ibirapuera da imposição à crise do trabalbo. 2013. Dissertação (Mestrado) - Faculdade de Filosofia, Letras e Ciências Humanas, Universidade de São Paulo. São Paulo, 2013.

KLUCK, E. G. J. O trabalho vai para o brejo: mobilização, migração e colapso da modernização. 2011. Dissertação (Mestrado) - Faculdade de Filosofia, Letras e Ciências Humanas, Universidade de São Paulo. São Paulo, 2011.

LEITE, A. C. G. A modernização do Vale do Jequitinhonha mineiro e o processo de formação do trabalhador "bóia-fria" em suas condições regionais de mobilização do trabalho. 2010. Dissertação (Mestrado) - Faculdade de Filosofia, Letras e Ciências Humanas, Universidade de São Paulo. São Paulo, 2010.

PITTA, F. T. Modernização retardatária e agroindústria sucroalcooleira paulista: o Proálcool como reprodução fictícia do capital em crise. 2012. Dissertação (Mestrado) Faculdade de Filosofia, Letras e Ciências Humanas, Universidade de São Paulo. São Paulo, 2012. 
RENTE, R. S. Região geográfica e o regional na literatura brasileira: a representação do sertão em Guimarães Rosa e os debates sobre a formação do Brasil. 2013. Dissertação (Mestrado) - Faculdade de Filosofia, Letras e Ciências Humanas, Universidade de São Paulo. São Paulo, 2013.

TOLEDO, C. A. A região das Lavras Baianas. 2008. Tese (Doutorado) - Faculdade de Filosofia, Letras e Ciências Humanas, Universidade de São Paulo. São Paulo, 2008.

TOLEDO, C. A.; BOECHAT, C. A.; HEIDEMANN, H. D. Vinte anos de um grupo de estudos do LABUR - Crise e crítica do sistema fetichista produtor de mercadoria e da modernização retardatária brasileira. Revista do Departamento de Geografia USP, São Paulo, v. esp. 30 Anos, p.154-70, 2012. Disponível em: <http://citrus.uspnet.usp. $\mathrm{br} / \mathrm{rdg} / \mathrm{ojs} /$ index.php/rdg/article/viewFile/380/443>.

RESUMO - O presente artigo discute a formação e crise do trabalho no Brasil tendo em vista suas especificidades. Este estudo revela a territorialização do capital que forma o Estado nacional como processo particular de expropriação - a região - marcada por relações de trabalho especificas, até que as condições sociais do assalariamento estivessem formadas. Por fim, trata da questão do ressurgimento do trabalho escravo no Brasil como forma de manifestação do colapso da modernização enquanto fenômeno mundializado e não específico ao território nacional.

PALAVRAS-CHAVE: Formação territorial, Trabalho, Escravismo, Região, Crise do capital.

ABSTRACT - The following article discusses the formation and the crisis of labor in Brazil, questioning about its specificity. This study reveals the territorialization of capital from which the national State arises as a particular process of expropriation - the region marked by specific relations of labor, up to the moment when the social conditions of wage labor were formed. At the end, it deals with the question of the reborn of slave labor in Brazil as a form of manifestation of the collapse of modernization as a global phenomenon and not as specific to the national territory.

KEYWORDS: Territorial formation, Labor, Slavery, Region, Capital crisis.

Heinz Dieter Heidemann é graduado em Geographie, Germanistik - Philipps-Universität, Marburg, e doutorado em Geografia - Philipps-Universität, Marburg. É professor da Universidade de São Paulo. @ - heideman@usp.br

Carlos de Almeida Toledo é graduado em Ciências Econômicas, mestre em Geografia Humana e doutor em Geografia Humana pela Universidade de São Paulo. É professor da Universidade de São Paulo. @ - catoledo@usp.br

Cássio Arruda Boechat é graduado em Letras pela Universidade Estadual Paulista "Júlio de Mesquita Filho", e em Ciências Sociais pela Universidade de São Paulo; mestre e doutor em Geografia Humana pela Universidade de São Paulo.

@ - cassio.boechat@gmail.com

Recebido em 25.6.2014 e aceito em 3.7.2014.

I, II , III Universidade de São Paulo. São Paulo/SP, Brasil. 